\title{
Sobre os ciclos de formação e sobre o ensino seriado
}

Valter Morigi*

\begin{abstract}
Pobres, verdadeiramente pobres, são os que têm pernas que se esqueceram de andar, como as asas das galinhas, que se esqueceram de voar. Pobres, verdadeiramente pobres, são os que não têm liberdade senão para escolher entre um e outro canal de televisão.
\end{abstract} Eduardo Galeano ${ }^{1}$ (2007, p. 169)

Resumo: $\mathrm{O}$ texto relata uma situação real vivenciada em uma escola da rede municipal de Porto Alegre, partindo desse gancho para uma breve análise da proposta de ensino por ciclos e também da escola seriada, apontando alguns elementos de comparação entre ambas, ressaltando a necessidade de transformações no processo comunicativo da escola com os familiares.

Palavras-chave: Ciclos de formação; Ensino seriado; Avaliação.

Abstract: The text reports an actual situation that happened in a school of Porto Alegre's municipal schools network, and uses it for a brief examination of the proposal of teaching by cycles and also of the school in series, pointing a few comparison elements

\footnotetext{
* Professor da rede municipal de Porto Alegre e estadual do RS. Doutorando em Educação, no PPGEdu/UFRGS, com pesquisa sobre Cidades Educadoras. E-mail: valtermorigi@gmail.com

1 Galeano, Eduardo. De pernas pro ar: a escola do mundo ao avesso. Porto Alegre: L\&PM, 2007, p. 169.
} 
between the two, and indicating the need for transformation in the communication process between the school and the students' families.

Keywords: Learning levels; Teaching in series; Assessment.

Escola Municipal de Porto Alegre, RS, mês de dezembro.

- Cada vez que ela chegava em casa e dizia que tinha realizado uma prova, eu esperava que ela tivesse más notícias para nós quando recebesse a correção. A qualquer momento esperávamos sermos chamados para que nos colocassem das dificuldades que ela tinha, até mesmo para ler, o que ela não consegue fazer direito até hoje.

Continua a mãe:

- Olha só, ela está terminando quase o fundamental e não lê um livro direito, não consegue realizar os trabalhos, para nós ela não está apta a terminar uma oitava série, por isso nós vamos tirá-la daqui, tentar colocar numa escola que realiza testes e dá notas, mas que puxe por ela, porque aqui não estamos vendo resultados. E o menino também vai, pois não queremos que ele passe por um ensino assim...

Dito isso, sem querer escutar muito as argumentações que tentamos levantar, a família se retira como os pareceres e sua carga grande de indignação. Sala de aula da escola, entrega de pareceres finais do ano, calor muito forte e ainda mais forte é o estupor que toma conta de nós.

De imediato, isso me remete ao Conselho de uma colega, antes dos Conselhos finais das C30's, o nível correspondente às oitavas séries. Era o seguinte: o pior castigo que eu posso fazer por eles é deixar que sigam adiante, assim sem condições, pois a vida vai cobrar deles os conhecimentos que não tiveram interesse em construir agora. Duvido que tenha qualquer escola de ensino médio que se preocupe com eles como nós aqui!

A Constituinte refletiu sobre o currículo, sobre a avaliação, sobre os princípios de convivência e sobre a gestão democrática, 
com a finalidade de combater a reprovação e a evasão, aproximar as pessoas e a escola, além de tornar a gestão participativa. A Escola Municipal de Ensino Fundamental Monte Cristo foi a primeira a ser organizada em Ciclos de Formação, em 1995, quando recém havia sido construída: uma equipe de professores iniciou o trabalho de pesquisas na comunidade para implantar os Ciclos, mesclando o conhecimento científico ao conhecimento popular. A partir daí, toda escola municipal nova que abrisse já seria organizada por Ciclos e, nas já estabelecidas, foi criado um processo que envolveu formação de professores e debates com a comunidade escolar.

\section{Currículo}

A Rede Municipal de Educação desenvolve seu currículo a partir do conhecimento e da participação da comunidade escolar. A pesquisa socioantropológica auxilia os professores a formarem um perfil da localidade a partir das falas de moradores, pais e alunos. O currículo não é composto unicamente pelas matérias ou conteúdos que os estudantes recebem em sala de aula, mas pelo conjunto de atividades teóricas e práticas que envolvem a vida escolar dentro e fora do espaço da escola e que interferem na formação do educando. Os Ciclos de Formação têm um currículo abrangente por não separar as vivências nem isolar o aluno.

Aprende-se quando se faz algo que tenha sentido para quem o faz, e dispensa-se aquilo que é irrelevante; portanto, busca-se nas diversas áreas de conhecimento aquilo que tenha relevância para a fase da vida do aluno. Isso, a partir de quatro fontes: a filosófica, a epistemológica, a sociopsicopedagógica e a socioantropológica. 


\section{Funcionamento dos Ciclos}

Nas Escolas Municipais de Porto Alegre, o Ensino Fundamental tem duração de nove anos, atendendo a alunos de 06 a 14 anos de idade. Os nove anos estão organizados em três Ciclos de três anos cada. O I Ciclo corresponde à infância, atende a crianças dos seis aos oito anos; o II Ciclo corresponde à pré-adolescência, recebe alunos dos 09 aos 11 anos de idade e, o III, à adolescência, alunos dos 12 aos 14 anos. A organização dos Ciclos é feita pelas fases da vida, ou seja, pelo tempo de existência do indivíduo e não necessariamente dividindo o tempo por anos.

\section{Avaliação}

Nos Ciclos, temos três tipos de avaliação: a Formativa, a Somativa e a Especializada.

- A Avaliação Formativa é composta pelas auto-avaliações dos alunos, das turmas e dos professores, também pela análise da família do estudante e pelo relatório descritivo que o professor faz de cada aluno. Considera-se, ainda, a assiduidade do aluno, sendo ela responsabilidade da família e cabendo ao educador registrá-la diariamente e enviá-la à secretaria da escola.

- A Avaliação Somativa é o resultado geral das Avaliações Formativas realizadas durante o ano. Ela é responsável pelo diagnóstico sobre o desenvolvimento da aprendizagem do aluno.

- A Avaliação Especializada é destinada àqueles alunos que exigem um acompanhamento mais específico e aprofundado do que o comumente necessário. Por isso, eles recebem um apoio educativo especial e muitas vezes especializado. Esse processo é realizado pelo Serviço de Orientação Pedagógica, com apoio do Laboratório de Aprendizagem e da Sala de Integração e Recursos.

A avaliação é contínua; todos os alunos têm uma pasta onde ficam arquivados seus trabalhos realizados na escola e que pode ser verificado o desenvolvimento do estudante. A escola por 
Ciclos da Formação garante ao aluno o direito à continuidade e término de seus estudos, acompanhando o desenvolvimento da turma.

\section{Turma de Progressão}

Nas Turmas de Progressão, o aluno pode avançar em qualquer época do ano para outra turma de progressão ou para determinado ano Ciclo, dependendo da avaliação feita pelo coletivo da escola e dependendo também de sua faixa etária.

\section{Laboratórios de Aprendizagem}

O aluno continua freqüentando sua turma e, no turno inverso ao da aula, freqüenta o Laboratório, que conta com professores especializados para esse atendimento, eleitos pelos outros professores, mediante a apresentação de um projeto de trabalho.

\section{Professor Itinerante}

Cada turma, numa escola por Ciclos de Formação, conta com a participação, além do professor referência, do professor itinerante. Este profissional não é um substituto do trabalho docente. É, longe disso, alguém que conhece, planeja e interfere, junto com o professor da turma, nas atividades de aula.

\section{Como era (e é) no Ensino Seriado...}

O ensino seriado foi desenvolvido no final do século XIX pelos tayloristas norte-americanos. Naquele momento, um importante educador, Joseph Mayer Rice, produziu as linhas da gestão racional do processo de aprendizagem. Um dos 
fundamentos elaborados por Rice é a crença no processo de adaptação dos homens à condiçôes previamente elaboradas pelos téenicos. Rice, como bom taylorista, acreditava que a escola puiblica tinba por função desenvolver e formatar homens para a industria nascente. Ao primário era reservado o dever de formar operários do tipo "bomem-boi"(disciplinados, sem muita inteligência, tal como escreven Taylor). Por este motivo, o professor do ensino fundamental transformou-se num mero técnico em reprodução de conteúdos e comportamentos exigidos pela induistria (RICCI, 2001, p. 01).

Nos primórdios da era industrial, a escola seriada servia como instrumento para o treinamento, a preparação da mão-deobra para a obediência de ordens. Por isso a enorme semelhança entre a organização da educação escolar e a organização dos sistemas de produção. A concepção do conhecimento na escola por séries é a de um produto pronto e acabado que deve ser ensinado, depositado, transferido aos alunos, pouco a pouco, em doses distribuídas em séries.

Tal qual uma linha de produção, os estudantes entram juntos na $\mathrm{l}^{\mathrm{a}}$ série e devem percorrer juntos o percurso para chegar ao final e saírem formados. A contribuição que os alunos trazem da vida não são levados em conta, pois se deve seguir uma sequiência de conteúdos programáticos espalhados pelas séries escolares. Em outras palavras, não há um resgate, uma valorização da educação da vida, dos conhecimentos que já estão com o aluno. O que importa é passar ao aluno - ensinar, transmitir saberes no mínimo 50\% (ou mais, em algumas escolas), em um tempo fixo - 200 dias letivos - para que aconteça a aprendizagem e haja a aprovação do aluno.

Há também a separação por disciplinas, onde cada uma delas é dona de um pedaço de conhecimento, fragmentado e desarticulado dos demais. E todas se julgam a mais importante e autônoma em relação às outras. Isso leva a um quase desuso de espaços coletivos, como laboratórios e bibliotecas, ou a uma 
utilização que apenas reforça essa repartição do saber. São disciplinas paradas, que não demonstram preocupação com a realidade em totalidade, fazendo com que o que se aprende na escola não influa na vida, pois não parte da realidade nem se remete a ela.

A medição do quanto os alunos aprenderam ou acumularam dos conteúdos é feita em exames que não se importam com o processo desenvolvido e sim com o escore obtido no resultado final. Se ocorrer de alguns ficarem abaixo do esperado, a solução é que esses repitam o processo feito, pois o problema está neles e não no sistema escolar. Por óbvio, a avaliação se faz sobre as partes em que está decomposta a educação nesse modelo. Entende-se que a escola seriada é uma transmissora de saberes técnicos, já no ensino ciclado, o conhecimento não é (ou não deveria ser) um fim, mas um meio.

\section{Breves conclusões sobre um tema sempre inconcluso}

"Se a educação sozinha não transforma a sociedade, sem ela, tampouco, a sociedade muda.” Paulo Freire (p. 31, 2000)

De modo geral, as críticas são no sentido desresponsabilização com a qualidade do ensino, ao permitir a progressão continuada dos alunos ao longo da sua escolaridade. O Instituto Nacional de Estudos e Pesquisas Educacionais (Inep) divulgou um relatório parcial de uma pesquisa que vem desenvolvendo com os pais de alunos das redes públicas de ensino. A partir da divulgação dessa pesquisa, que tem por objetivo retratar a escola pública na opinião dos pais, vários jornais apontam a queixa com a qualidade do ensino e a sua relação com a escola organizada por ciclos.

Isso é um fato que requer certo cuidado. Não podemos atribuir às mazelas da educação básica aos ciclos, principalmente, considerando que grande parte sistema de ensino público brasileiro ainda vive sob a égide da organização curricular por série. 
As mesmas dificuldades encontradas no início da implantação do ensino ciclado prosseguem até os dias atuais. Mesmo com problemas como a falta de comunicação clara com as famílias, há alguns pontos positivos que se destacam: a valorização do aluno na individualidade; a elevação da auto-estima pelo fato do aluno não ser avaliado através de notas, mas sim de conceitos; a adequação idade e ciclo; a presença de mais recursos humanos envolvidos no processo.

Entendemos, porém, que, a construção de uma nova prática educativa demanda sem dúvida certo tempo e paciência pedagógica, mas precisamos compreender que esta construção se dá no exercício da própria prática docente no dia-a-dia da escola, mesmo que as políticas públicas não ofereçam a preparação necessária para que uma educação de qualidade aconteça.

O fundamento dos Ciclos de Formação é a convicção de que todos podem aprender. O que há de tão misterioso para as famílias que não pode ser entendido? Basicamente, os Ciclos partem da compreensão das fases da vida do aluno e do respeito aos conhecimentos que ele desenvolveu junto à sua família, aos seus amigos e à cidade para, então, construir o dia-a-dia na escola. E isso precisa ser explicado para pais e mães que cresceram e se formaram com a didática, os pressupostos e as avaliaçóes do ensino seriado.

E esse modelo parte do pressuposto de que o conhecimento pode ser dosado e selecionado pelos professores somente sem que alunos e pais participem, a não ser quando for para repreensões dos filhos ou para angariar recursos, quando o poder público não cumpre seu dever de ofertar e sustentar a educação pública.

Infelizmente, em ambas as propostas, aos pais parece estar destinado um papel secundário, e mesmo esse a ser definido pelos donos do saber, os mestres que não apontam para uma possibilidade de ruptura dessas relações. Quem deveria ser sujeito do processo educativo acaba relegado a ser objeto.

A necessidade de transformação, de (re)adequação da escola ao tempo presente é uma das grandes preocupaçốes que 
aflige a sociedade atual. As últimas alterações do sistema educacional brasileiro aconteceram muito pela falência do modelo atual e pouco de uma decisão pensada e planejada na busca de uma nova escola e uma nova educação.

O desafio é pensar uma escola de um novo tipo e debater sobre isso, articulado sempre com o tipo de sociedade que queremos para viver e como acreditamos ser possível construí-la, em conjunto com ela e não apresentar algo pronto sem a participação dos cidadãos, sejam pais, mães, responsáveis, moradores das comunidades onde se localizam as escolas. Se, o modelo de ensino em ciclos que vêm sendo vivenciado em nossas escolas não responde aos anseios de uma nova educação, é preciso que através de estudos, pesquisas e com muita discussão com toda a comunidade escolar, possamos chegar a um modelo que de educação inclusiva e de qualidade.

\section{Referências}

CADERNOS PEDAGÓGICOS SMED, Porto Alegre, n. 9, dez. 1996.

GALEANO, Eduardo. De Pernas Pro Ar. a Escola do Mundo ao Avesso. Porto Alegre: Editora L\&PM, 2009.

KRUG, Andréa. Ciclos de Formação - Uma Proposta Transformadora. Porto Alegre: Mediação, 2002.

RICCI, Rudá. Da seriação aos ciclos. Belo Horizonte: CPP, 2001. 